\title{
A plethora of lesion-replicating DNA polymerases
}

\author{
Roger Woodgate ${ }^{1}$ \\ Section on DNA Replication, Repair and Mutagenesis, National Institute of Child Health and Human Development, \\ National Institutes of Health, Bethesda, Maryland 20892-2725 USA
}

Lesions in DNA often pose considerable impediments to genome duplication. To overcome this block to DNA replication, cells utilize specialized accessory factors that allow the synthesis of nascent DNA chains opposite the blocking lesion. Recent studies suggest that many of the key participants in translesion DNA synthesis belong to a large family of structurally related proteins that are found in prokaryotes, archaea, and eukaryotes. Phylogenetic analysis of these proteins suggests that they can be subdivided broadly into four groups typified by Escherichia coli UmuC, E. coli DinB, Saccharomyces cerevisiae Rev1, and the $S$. cerevisiae Rad30 protein. In the past, the molecular mechanism of translesion DNA synthesis has been one of the major unsolved problems in DNA repair. In the last 12 months, however, we have witnessed rapid development in our understanding of this fascinating process, with the discovery that E. coli UmuC, DinB, S. cerevisiae Rad30, and a human homolog of Rad30 are all novel DNA polymerases, most of which are capable of replicating damaged DNA (Tang et al. 1998, 1999; Johnson et al. 1999b; Masutani et al. 1999a; Wagner et al. 1999). These findings suggest that the process of translesion DNA synthesis is conserved from bacteria to humans (Fig. 1).

\section{Translesion DNA synthesis in $E$. coli}

Translesion DNA synthesis is best understood at the genetic level in E. coli, which is perhaps why the process appears more complex when compared to the other systems. Of the phylogenetically related proteins involved in translesion DNA synthesis, those belonging to the DinB family are the most widespread, being found in all three kingdoms of life; the prototype being the E. coli DinB protein (Kulaeva et al. 1996). dinB was sequenced 4 years ago by Haruo Ohmori and colleagues (1995) who called it $\operatorname{din} P$. It was later discovered that $\operatorname{din} P$ was allelic with $\operatorname{din} B$, a damage-inducible gene identified by Kenyon and Walker (1980) some 15 years earlier (Kim et al. 1997). Until recently, very little was known about $\operatorname{din} B$ function apart from the fact that it was somehow involved in the mutagenesis of undamaged bacte-

${ }^{1}$ E-MAIL woodgate@helix.nih.gov; FAX (301) 594-1135. riophage $\lambda$, when grown on a UV-irradiated host (Brotcorne-Lannoye and Maenhaut-Michel 1986). Deletion of $\operatorname{din} B$ results in no obvious phenotype with respect to chromosomal mutagenesis, but overproduction of DinB leads to a dramatic increase in -1 frameshift mutations on an episomal $\mathrm{F}^{\prime}$ plasmid (Kim et al. 1997), suggesting a potential role for DinB in spontaneous mutagenesis. Such a role is supported by the recent findings of Wagner et al. (1999), who have purified a histidine-tagged DinB protein and demonstrated that it possesses intrinsic DNA polymerase activity. As the fourth DNA polymerase identified in E. coli, Wagner and colleagues (1999) have termed DinB, DNA polymerase IV (Pol IV). Pol IV is not processive; rather it adds template-directed nucleotides in a distributive manner. Interestingly, Pol IV appears to possess the ability to efficiently extend a $3^{\prime}$ primer terminus that is misaligned with a bulged template. Such an activity leads to a replication product that is 1 nucleotide shorter than that expected and is consistent with the propensity of DinB-dependent -1 frameshift events observed in vivo (Kim et al. 1997; Wagner et al. 1999). Whether Pol IV has the ability to extend the $3^{\prime}$ termini at other sites, such as those found opposite DNA lesions, remains to be determined. However, given that a mispaired/bulged template may share structural characteristics with those found opposite certain DNA lesions, it does not seem unreasonable to expect such an activity, at least in vitro.

It is clear, however, that in vivo, most translesion DNA synthesis is dependent on the damage-inducible heterotrimeric complex of $\mathrm{UmuD}_{2}{ }_{2} \mathrm{C}$ (for a recent review, see Smith and Walker 1998). E. coli strains with inactivating mutations in their umu genes do not exhibit the dramatically elevated mutation rate seen when wildtype cells are exposed to various mutagens (Kato and Shinoura 1977; Steinborn 1978), indicating that the Umu-dependent pathway of translesion DNA synthesis is normally error prone. Although advances have been made in unraveling the multiple levels of regulation imposed on the Umu-dependent pathway, to keep the level of spontaneous mutagenesis to a minimum (Woodgate and Levine 1996), the actual mechanism of how translesion DNA synthesis occurs in the cell has remained largely unsolved. The major stumbling block was the inability to purify quantities of a soluble and active 


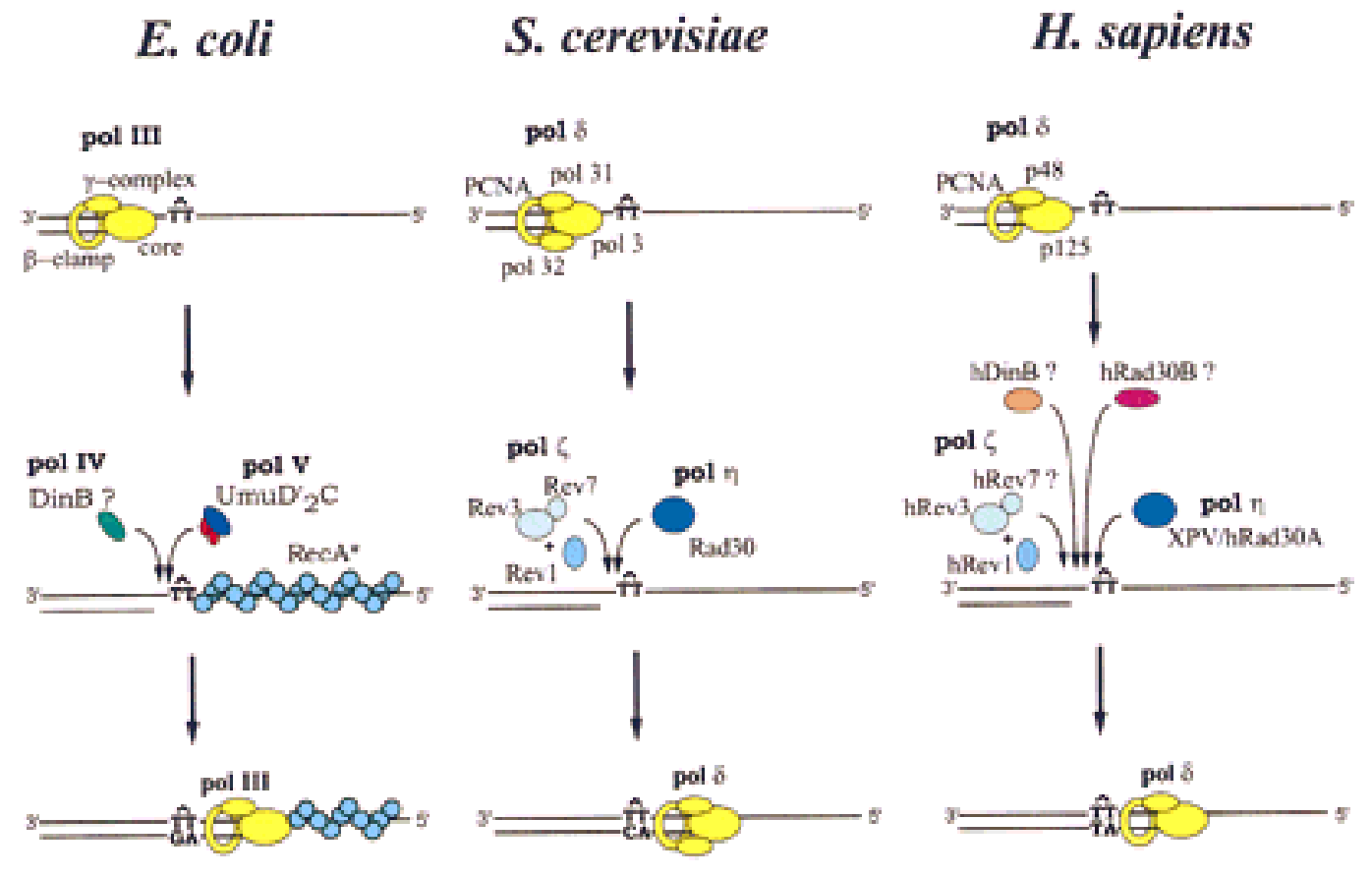

\section{Error-free or Error-prone bypass}

Figure 1 Conserved mechanism of translesion DNA synthesis from E. coli and S. cerevisiae to humans. The underlying premise of this model is that the cell's highly processive replicase, unable to traverse the blocking lesion, dissociates from the template at the site of the lesion and is replaced by one of the distributive lesion-replicating polymerases described herein. These polymerases add 1 or 2 nucleotides to the nascent DNA chain opposite the lesion and, as a consequence, alleviate the kinetic block to replication. Once this is achieved, the cell's main replicase is able to reassemble on the 3' primer terminus and resumes its job of genome duplication. Depending on the lesion encountered and the fidelity of the DNA polymerase utilized for translesion replication, the bypass reaction will either be error free or error prone.

UmuC protein. Recently, two groups, each using a different approach, independently overcame this problem. Tang et al. (1998) purified a native complex of UmuC coupled to a dimer of $\mathrm{UmuD}^{\prime}\left(\mathrm{UmuD}_{2}{ }_{2} \mathrm{C}\right.$ complex), whereas Reuven et al. (1998) purified a maltose-binding protein/UmuC fusion protein. Both strategies resulted in the reconstitution of translesion DNA synthesis in vitro. Somewhat surprisingly, the native and highly purified $\mathrm{UmuD}_{2}{ }_{2} \mathrm{C}$ complex purified by Tang et al. (1998) was able to perform translesion DNA synthesis in the absence of exogenous DNA polymerase. Although this polymerase activity was distinct from either DNA Pol II or Pol III, it was consistent with previous genetic models, suggesting that $\mathrm{UmuD}_{2}{ }_{2} \mathrm{C}$ might modify one of $E$. coli's DNA polymerases, so as to allow bypass (Bridges and Woodgate 1985). Very recently, however, Tang et al. (1999) have eliminated this possibility by purifying $\mathrm{UmuD}^{\prime}{ }_{2} \mathrm{C}$ from a strain carrying a temperature-sensitive dnaE (DNA Pol III $\alpha$-catalytic subunit) allele and a $\Delta p o l B$ (DNA Pol II) deletion. DNA polymerase activity was still observed at the restrictive temperature when Pol IIIts was inactivated, indicating that $\mathrm{UmuD}_{2}{ }_{2} \mathrm{C}$ is a bona fide polymerase. In further support of this notion, $\mathrm{a} \mathrm{UmuD}_{2} \mathrm{C}$ complex containing a nonfunctional UmuC104 protein (Steinborn 1978) was unable to bypass a single abasic site in the template DNA. As the fifth E. coli DNA polymer- ase discovered, Tang et al. (1999) have called $\mathrm{UmuD}_{2}{ }_{2} \mathrm{C}_{\text {, }}$ DNA polymerase V (Pol V). Given the structural similarity of UmuC to E. coli Pol IV and S. cerevisiae Pol $\eta$ (see below), it seems likely that the active site of the enzyme resides in UmuC and that $\mathrm{UmuD}_{2}{ }_{2}$ is a stimulatory subunit of a larger complex. Indeed, the activity of Pol V is greatly enhanced by the presence of the $\beta$-clamp and $\gamma$-clamp loader complex of DNA Pol III and RecA protein, suggesting that Pol V is most active in its holoenzyme form (Tang et al. 1999).

\section{Translesion DNA synthesis in S. cerevisiae}

In a similar manner, $S$. cerevisiae also appears to utilize two main pathways of lesion bypass. One mode is catalyzed by Rev3 and Rev7, which together form Pol $\zeta$ (Nelson et al. 1996a). In vivo, Pol $\zeta$-dependent translesion replication also requires the activity of the Rev1 protein (Lawrence and Christensen 1976). Although neither Rev3 nor Rev7 shares any identity with E. coli UmuC or DinB, the amino terminus of Rev1 shares limited homology to both proteins (Larimer et al. 1989; Johnson et al. 1999b). Genetic and biochemical characterization of Rev1 revealed that it is a bifunctional protein and is best characterized for its template-directed deoxycytidyl transferase activity (Nelson et al. 1996b). This transfer- 
ase activity is particularly useful at abasic sites where the $\mathrm{C} \cdot \mathrm{X}$ mispair is easily extended by Pol $\zeta$ (Nelson et al. 1996b). This activity differs from terminal transferase, which adds nucleotides in a nontemplated manner, and although the term deoxycytidyl transferase is specific, another way of looking at it is that Rev1 simply has limited DNA polymerase activity.

The alternative mode of translesion replication appears to be facilitated by Rad30. Like Rev1, Rad30 shares structural homology with both E. coli UmuC and DinB proteins (McDonald et al. 1997; Roush et al. 1998). Genetic analysis of $R A D 30$ clearly places it in the RAD6 epistasis group of $S$. cerevisiae proteins involved in postreplication repair (McDonald et al. 1997). Furthermore, Rad30 appears to function in a pathway that is independent of Rev1, Rev3, or Rev7. Depending on the mutagen and the mutational assay employed, Rad30 was classified as being involved in either error-free or errorprone pathways of DNA repair (McDonald et al. 1997; Roush et al. 1998).

The latter paradox can be explained by the recent findings of Johnson et al. (1999b), who have characterized the biochemical properties of the Rad30 protein. As Rad30 shares limited structural homology with Rev1, these workers investigated the possibility that the Rad30 and Rev1 proteins might exhibit similar dCTP transferase activities. Analysis revealed, however, that in addition to dCTP, Rad30 was able to incorporate dGTP, dATP, and TTP in a template-directed manner, indicating that the $S$. cerevisiae Rad30 protein is a bona fide polymerase, Pol $\eta$ (Johnson et al. 1999b). In vitro, Pol $\eta$-dependent replication of a cis-syn thymine-thymine dimer was shown to be highly accurate, with dAMP being incorporated preferentially opposite the lesion, thereby potentially explaining the apparent error-free role for Rad30 in DNA repair. At the present time, however, there have been no reports on the ability of $\operatorname{Rad} 30$ to accurately replicate other types of DNA damage, and it is conceivable that at these lesions, Pol $\eta$-dependent translesion DNA synthesis will be considered error prone.

\section{Translesion DNA synthesis in Homo sapiens}

On the basis of their finding that Rad30 replicates across cis-syn pyrimidine dimers both efficiently and with apparently high fidelity, Johnson et al. (1999b) hypothesized that defects in the human equivalent of $\operatorname{Rad} 30$ might result in the xeroderma pigmentosum variant (XP$\mathrm{V})$ phenotype. Humans exhibiting the XP-V phenotype have a higher than normal incidence of skin cancer, and cultured cells are hypermutable after exposure to ultraviolet (UV) light (Raha et al. 1996; McGregor et al. 1999). Several lines of research suggest that the defects in XP-V cells lie in their reduced ability to accurately replicate damaged DNA (Svoboda and Vos 1995; Cordeiro-Stone et al. 1997; Svoboda et al. 1998). Indeed, utilizing a singlestranded vector containing a unique acetyl aminofluorene (AAF) adduct, Cordonnier et al. recently demonstrated that unlike extracts from wild-type cells, which are proficient for translesion DNA synthesis, those made from XP-V cells exhibited a greatly reduced ability to bypass the single AAF adduct (Cordonnier et al. 1999).

The prediction that human homologs of Rad30 would be defective in patients with the XP-V phenotype was fulfilled very recently (Johnson et al. 1999a; Masutani et al. 1999a,b). In an elegant paper, Masutani et al. (1999a) described a cell-free assay that they used to identify and purify a protein from HeLa cells that restored translesion replicating activity to XP-V extracts. Microsequencing of proteolytic fragments of the complementing protein and the subsequent cloning of the gene revealed that the XP-V correcting protein shared $\sim 20 \%$ identity and $~ 31 \%$ similarity to the $S$. cerevisiae $\operatorname{Rad} 30$ protein (Masutani et al. 1999b). Like S. cerevisiae Rad30, the human Rad30 homolog possesses intrinsic DNA polymerase activity and is able to perform accurate translesion replication of a cis-syn thymine-thymine dimer (Masutani et al. 1999a). Analysis of five XP-V cell lines revealed that in all cases, the human $R A D 30$ gene was either truncated and/or had reduced expression (Masutani et al. 1999b) (Fig. 2).

Following up on their earlier suggestion, Johnson et al.

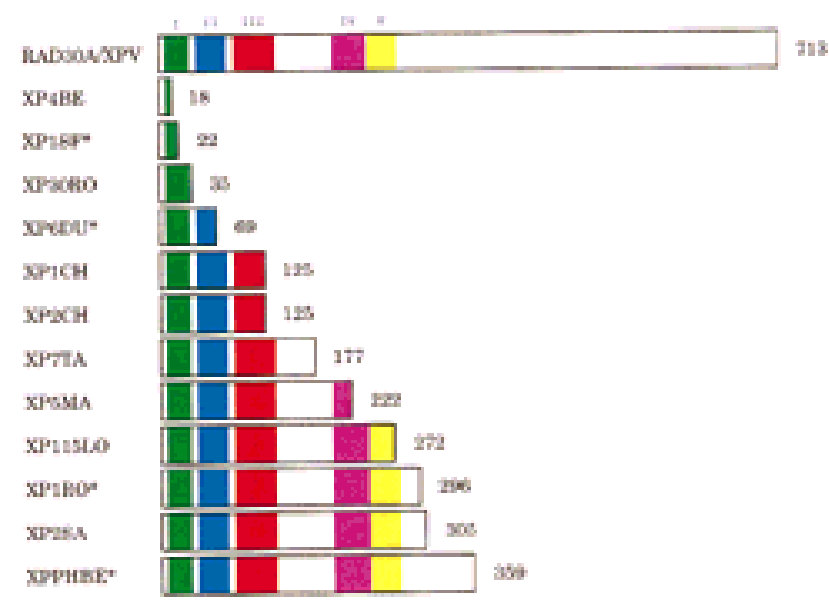

Figure 2. Localization of conserved motifs in the human Rad30A/XPV protein and the identification of mutant proteins that result to the xeroderma pigmentosum variant phenotype in humans. Based on the alignment of E. coli UmuC, E. coli DinB, S. cerevisiae Rev1, and S. cerevisiae Rad30 proteins, five motifs can be identified in these structurally related proteins (Kulaeva et al. 1996; Johnson et al. 1999c; Masutani et al. 1999b; McDonald et al. 1999). The conserved five motifs in the human Rad30A/XPV protein are identified by roman numerals and are colored differently. The wild-type Rad30A/XPV protein is 713 amino acids long, and most of the inactivating mutations found in humans exhibiting the XP-V phenotype result in a severely truncated protein. The position at which the mutant protein deviates from the wild-type sequence is indicated at the right of each protein. Mutations in human cell lines XP4BE, XP30RO, XP7TA, XP2SA, and XP1RO were identified by Masutani et al. (1999b) and mutations in XP1CH, XP2CH, XP115LO, XP30RO, XPPHBE, XP6DU, and XP1SF were identified by Johnson et al. (1999a). Most of the RAD30A mutations found in the $12 \mathrm{XP}-\mathrm{V}$ cell lines were homozygous. The exceptions were those in cell lines indicated with an asterisk, which are heterozygous (for specific details, see Masutani et al. 1999b; Johnson et al. 1999a). 
(1999a) have independently cloned a human homolog of Rad30 and have sequenced the gene in eight XP-V patients. They also found mutations in RAD30 that resulted in severe truncations of the RAD30/XPV protein (Fig. 2). As a result of both studies, the RAD30 gene in 12 $\mathrm{XP}-\mathrm{V}$ patients has been sequenced. In all cases, reduced expression of the wild-type protein or expression of a truncated protein was observed, leading to the unequivocal conclusion that defects in the gene lead to the XP-V phenotype (Johnson et al. 1999a; Masutani et al. 1999b).

However, the story is far from complete. In an independent study, McDonald et al. (1999) have identified a second human homolog of $S$. cerevisiae RAD30, termed $R A D 30 B$. The RAD30B protein shares roughly the same degree of identity to $S$. cerevisiae RAD30 as the RAD30A/XPV protein and, although not mutated in $\mathrm{XP}-\mathrm{V}$ patients, is likely, given the similarity to other lesion-replicating DNA polymerases, to be yet another human DNA polymerase. As they say, 'All good things come in threes,' and that appears to be the case with human Rad30 homologs. Database searches reveal a third homolog that is as equally related to $S$. cerevisiae Rad30 as the human RAD30A/XPV and the RAD30B proteins described above. Phylogenetic analysis of this protein suggest that it is, however, more closely related to the E. coli DinB protein (E. coli Pol IV) and should perhaps be considered a human DinB homolog rather than a Rad30 homolog (McDonald et al. 1999).

The functional relevance of these paralogs is presently unknown, but it seems reasonable to speculate that they might be required to replicate specific types of DNA damage. For example, although the XPV protein purified by Masutani et al. (1999a) was able to bypass a cis-syn pyrimidine dimer, it was unable to replicate past another UV photoproduct, a (6-4) pyrimidine-pyrimidone dimer, suggesting that bypass activity may be lesion specific to some extent. Presumably such translesion replication activities are performed by the aforementioned Rad30 paralogs or the human homolog of S. cerevisiae, Rev3, that was reported recently (Gibbs et al. 1998).

\section{A common mechanism of translesion DNA synthesis}

These recent findings suggest that bacteria, yeast, and humans accomplish translesion DNA synthesis by a common mechanism (Fig. 1). In each case, the organism's main replicase, which is unable to bypass the lesion, dissociates from the template, leaving a $3^{\prime}$ primer terminus prior to the lesion. Translesion replication is then catalyzed by one of the recently described DNA polymerases. E. coli may employ DinB (Pol IV), but most of the time, translesion DNA synthesis is performed by $\mathrm{UmuD}_{2} \mathrm{C}(\mathrm{Pol} \mathrm{V})$ in concert with activated RecA $\left(\right.$ RecA $\left.^{\star}\right)$ and the $\beta-\gamma$ complex of Pol III (not shown). In $S$. cerevisiae, translesion DNA synthesis is either carried out by Rev3/Rev7 (Pol ל), together with Rev1, or by $\operatorname{Rad} 30$ (Pol $\eta$ ). Translesion replication in humans is less well characterized, and the polymerase utilized ultimately is likely to depend on the type of lesion encountered. All of the novel lesion-replicating polymerases ap- pear to lack significant processivity and probably dissociate from the template shortly after translesion replication occurs. This allows the main replicase to complete faithful genome duplication.

How accurately each DNA lesion is replicated clearly depends on the type of DNA lesion encountered; some like a cis-syn pyrimidine dimer still retain coding capacity, whereas others like 6-4 photoproducts or abasic sites do not and are highly mutagenic. However, the replication accuracy also depends on the lesion-replicating DNA polymerase utilized to bypass the DNA damage. Some, like $S$. cerevisiae Pol $\eta$ when replicating a cis-syn pyrimidine dimer, will be considered error free, whereas others, such as Pol $\zeta$, when replicating the very same lesion, will be error prone. Although to some extent this distinction may be a question of semantics as even a mutation frequency of 1 error per 100 dimers replicated is considerably higher than that of normal replication, with 1 error per $10^{10}$ nucleotides replicated (Schaaper 1993). Clearly, the best way to avoid the generation of mutations is to repair the DNA by the surfeit of truly error-free repair pathways before it is replicated (for review, see Friedberg et al. 1995). Under conditions in which repair is not possible, each organism appears to have a choice of lesion-replicating DNA polymerases. The use of a potentially error-prone polymerase in a unicellular organism like E. coli not only allows the cell to survive, but it may also enhance the overall 'fitness' of the organism under times of environmental stress (Echols 1981). However, this is not necessarily true for more complex organisms, in which the generation of mutations often has secondary consequences and may ultimately result in cancer and/or cell death. This is most obvious in XP-V patients, in which the delicate balance between error-free and error-prone bypass has been skewed in favor of an error-pone pathway that results in a higher incidence of cancer.

Now that it has been established that the key participants in translesion replication are DNA polymerases, the next step will be to determine their respective lesionreplicating specificity, as well as how they are temporally regulated, so that the cell preferentially utilizes a high-fidelity polymerase over one that is more error prone. If the past 12 months are anything to go by, then we may have the answer soon.

\section{Acknowledgments}

I thank Chris Lawrence, Alan Lehmann, Fumio Hanaoka, and all the members of my laboratory for the many helpful discussions that culminated in this article, and Jonathan Epstein and John McDonald for help in generating Figure 2.

\section{References}

Bridges, B.A. and R. Woodgate. 1985. Mutagenic repair in Escherichia coli: Products of the recA gene and of the $u m u D$ and umuC genes act at different steps in UV-induced mutagenesis. Proc. Natl. Acad. Sci. 82: 4193-4197.

Brotcorne-Lannoye, A. and G. Maenhaut-Michel. 1986. Role of RecA protein in untargeted UV mutagenesis of bacterio- 
phage $\lambda$ : Evidence for the requirement for the $\operatorname{din} B$ gene. Proc. Natl. Acad. Sci. 83: 3904-3908.

Cordeiro-Stone, M., L.S. Zaritskaya, L.K. Price, and W.K. Kaufmann. 1997. Replication fork bypass of a pyrimidine dimer blocking leading strand DNA synthesis. I. Biol. Chem. 272: 13945-13954.

Cordonnier, A.M., A.R. Lehmann, and R.P.P. Fuchs. 1999. Impaired translesion synthesis in xeroderma pigmentosum variant extracts. Mol. Cell. Biol. 19: 2206-2211.

Echols, H. 1981. SOS functions, cancer and inducible evolution. Cell 25: 1-2.

Friedberg, E.C., G.C. Walker, and W. Siede. 1995. DNA repair and mutagenesis. American Society for Microbiology, Washington, DC.

Gibbs, P.E., W.G. McGregor, V.M. Maher, P. Nisson, and C.W. Lawrence. 1998. A human homolog of the Saccharomyces cerevisiae REV3 gene, which encodes the catalytic subunit of DNA polymerase $\zeta$. Proc. Natl. Acad. Sci. 95: 6876-6880.

Johnson, R.E., C.M. Kondratick, S. Prakash, and L. Prakash. 1999a. $h R A D 30$ mutations in the variant form of Xeroderma Pigmentosum. Science 285: 263-265.

Johnson, R.E., S. Prakash, and L. Prakash. 1999b. Efficient bypass of a thymine-thymine dimer by yeast DNA polymerase, poln. Science 283: 1001-1004.

-1999c. Requirement of DNA polymerase activity of yeast Rad30 protein for its biological function. J. Biol. Chem. 274: 15975-15977.

Kato, T. and Y. Shinoura. 1977. Isolation and characterization of mutants of Escherichia coli deficient in induction of mutations by ultraviolet light. Mol. \& Gen. Genet. 156: 121-131.

Kenyon, C.J. and G.C. Walker. 1980. DNA-damaging agents stimulate gene expression at specific loci in Escherichia coli. Proc. Natl. Acad. Sci. 77: 2819-2823.

Kim, S.R., G. Maenhaut-Michel, M. Yamada, Y. Yamamoto, K. Matsui, T. Sofuni, T. Nohmi, and H. Ohmori. 1997. Multiple pathways for SOS-induced mutagenesis in Escherichia coli: An overexpression of $\operatorname{din} B / \operatorname{din} P$ results in strongly enhancing mutagenesis in the absence of any exogenous treatment to damage DNA. Proc. Natl. Acad. Sci. 94: 13792-13797.

Kulaeva, O.I., E.V. Koonin, J.P. McDonald, S.K. Randall, N. Rabinovich, J.F. Connaughton, A.S. Levine, and R. Woodgate. 1996. Identification of a DinB/UmuC homolog in the archeon Sulfolobus solfataricus. Mutat. Res. 357: 245253.

Larimer, F.W., J.R. Perry, and A.A. Hardigree. 1989. The REV1 gene of Saccharomyces cerevisiae: Isolation, sequence and functional analysis. J. Bacteriol. 171: 230-237.

Lawrence, C.W. and R. Christensen. 1976. UV mutagenesis in radiation-sensitive strains of yeast. Genetics 82: 207-232.

Masutani, C., M. Araki, A. Yamada, R. Kusumoto, T. Nogimori, T. Maekawa, S. Iwai, and F. Hanaoka. 1999a. Xeroderma pigmentosum variant (XP-V) correcting protein from HeLa cells has a thymine dimer bypass DNA polymerase activity. EMBO T. 18: 3491-3501.

Masutani, C., R. Kusumoto, A. Yamada, N. Dohmae, M. Yokoi, M. Yuasa, M. Araki, S. Iwai, K. Takio, and F. Hanaoka. $1999 \mathrm{~b}$. The XPV (xeroderma pigmentosum variant) gene encodes human DNA polymerase $\eta$. Nature 399: 700-704.

McDonald, J.P., A.S. Levine, and R. Woodgate. 1997. The Saccharomyces cerevisiae RAD30 gene, a homologue of Escherichia coli $\operatorname{din} B$ and umuC, is DNA damage inducible and functions in a novel error-free postreplication repair mechanism. Genetics 147: 1557-1568.

McDonald, J.P., V. Rapic-Otrin, J.A. Epstein, B.C. Broughton, X. Wang, A.R. Lehmann, D.J. Wolgemuth, and R. Woodgate. 1999. Novel human and mouse homologs of Saccharomyces cerevisiae DNA polymerase $\eta$. Genomics 60: 20-30.

McGregor, W.G., D. Wei, V.M. Maher, and J.J. McCormick. 1999. Abnormal, error-prone bypass of photoproducts by xeroderma pigmentosum variant cell extracts results in extreme strand bias for the kinds of mutations induced by UV light. Mol. Cell. Biol. 19: 147-154.

Nelson, J.R., C.W. Lawrence, and D.C. Hinkle. 1996a. Thymine-thymine dimer bypass by yeast DNA polymerase $\zeta$. Science 272: 1646-1649.

- 1996b. Deoxycytidyl transferase activity of yeast REV1 protein. Nature 382: 729-731.

Ohmori, H., E. Hatada, Y. Qiao, M. Tsuji, and R. Fukuda. 1995. $\operatorname{din} P$, a new gene in Escherichia coli, whose product shows similarities to UmuC and its homologues. Mutat. Res. 347: $1-7$.

Raha, M., G. Wang, M.M. Seidman, and P.M. Glazer. 1996. Mutagenesis by third-strand-directed psoralen adducts in repairdeficient human cells: High frequency and altered spectrum in a xeroderma pigmentosum variant. Proc. Natl. Acad. Sci. 93: 2941-2946.

Reuven, N.B., G. Tomer, and Z. Livneh. 1998. The mutagenesis proteins UmuD' and UmuC prevent lethal frameshifts while increasing base substitution mutations. Mol. Cell 2: 191199.

Roush, A.A., M. Suarez, E.C. Friedberg, M. Radman, and W. Siede. 1998. Deletion of the Saccharomyces cerevisiae gene RAD30 encoding an Escherichia coli DinB homolog confers UV radiation sensitivity and altered mutability. Mol. \& Gen. Genet. 257: 686-692.

Schaaper, R.M. 1993. Base selection, proofreading, and mismatch repair during DNA replication in Escherichia coli. J. Biol. Chem. 268: 23762-23765.

Smith, B.T. and G.C. Walker. 1998. Mutagenesis and more: umuDC and the Escherichia coli SOS response. Genetics 148: $1599-1610$.

Steinborn, G. 1978. uvm mutants of Escherichia coli K12 deficient in UV mutagenesis. I. Isolation of uvm mutants and their phenotypical characterization in DNA repair and mutagenesis. Mol. \& Gen. Genet. 165: 87-93.

Svoboda, D.L. and J.M. Vos. 1995. Differential replication of a single, UV-induced lesion in the leading or lagging strand by a human cell extract: fork uncoupling or gap formation. Proc. Nat1. Acad. Sci. 92: 11975-11979.

Svoboda, D.L., L.P. Briley, and J.M. Vos. 1998. Defective bypass replication of a leading strand cyclobutane thymine dimer in xeroderma pigmentosum variant cell extracts. Cancer Res. 58: 2445-2448.

Tang, M., I. Bruck, R. Eritja, J. Turner, E.G. Frank, R. Woodgate, M. O'Donnell, and M.F. Goodman. 1998. Biochemical basis of SOS-induced mutagenesis in Escherichia coli: Reconstitution of in vitro lesion bypass dependent on the $\mathrm{UmuD}^{\prime}{ }_{2} \mathrm{C}$ mutagenic complex and RecA. Proc. Natl. Acad. Sci. 95: 9755-9760.

Tang, M., X. Shen, E.G. Frank, M. O'Donnell, R. Woodgate, and M.F. Goodman. 1999. UmuD' ${ }_{2} \mathrm{C}$ is an error-prone DNA polymerase, Escherichia coli DNA pol V. Proc. Nat1. Acad. Sci. 96: 8919-8924.

Wagner, J., P. Gruz, S.R. Kim, M. Yamada, K. Matsui, R.P.P. Fuchs, and T. Nohmi. 1999. The dinB gene encodes an novel Escherichia coli DNA polymerase (DNA pol IV) involved in mutagenesis. Mol Cell 40: 281-286.

Woodgate, R. and A.S. Levine. 1996. Damage inducible mutagenesis: recent insights into the activities of the Umu family of mutagenesis proteins. In Cancer surveys: Genetic instability in cancer (ed.T. Lindahl), pp. 117-140. Cold Spring Harbor Laboratory Press, Cold Spring Harbor, NY. 


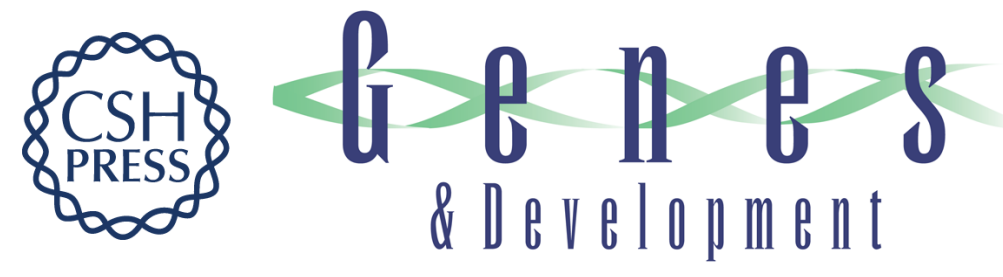

\section{A plethora of lesion-replicating DNA polymerases}

Roger Woodgate

Genes Dev. 1999, 13:

References This article cites 33 articles, 23 of which can be accessed free at: http://genesdev.cshlp.org/content/13/17/2191.full.html\#ref-list-1

License

Email Alerting

Receive free email alerts when new articles cite this article - sign up in the box at the top Service right corner of the article or click here.

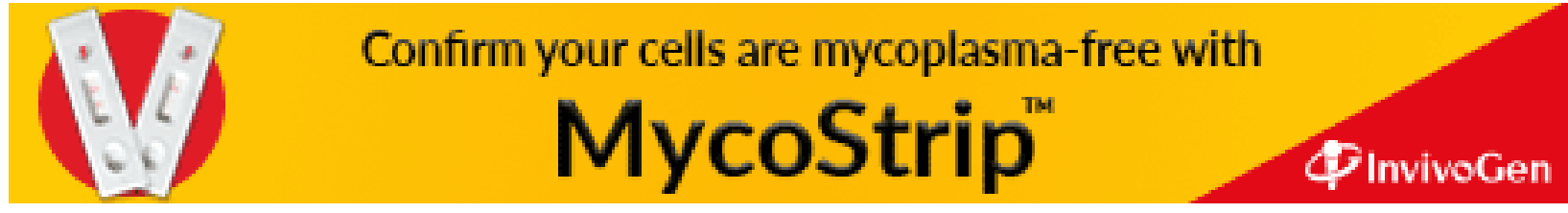

